Case Report

\title{
Philadelphia Translocation in MDS: A Case Report and a Brief Review of the Literature Looking at Its Prevalence, Disease Progression, and Treatment Options
}

\author{
Lakshmi Ramya Chelapareddy (i) and Sandeep Sen \\ SSM Health St. Mary's Hospital, St. Louis, Missouri 63117, USA \\ Correspondence should be addressed to Lakshmi Ramya Chelapareddy; dr.ramyachelapareddy@gmail.com
}

Received 3 June 2018; Revised 17 October 2018; Accepted 8 November 2018; Published 22 November 2018

Academic Editor: Pier P. Piccaluga

Copyright (C) 2018 Lakshmi Ramya Chelapareddy and Sandeep Sen. This is an open access article distributed under the Creative Commons Attribution License, which permits unrestricted use, distribution, and reproduction in any medium, provided the original work is properly cited.

Myelodysplastic syndrome (MDS) is a group of clonal disorders characterized by ineffective and dysplastic hematopoiesis in the bone marrow with variable risk of progression to leukemia. MDS is characterized by specific karyotypic and molecular abnormalities. The $\mathrm{t}(9: 22)$ Philadelphia translocation is not a common abnormality found in MDS, and it is not included in the prognostic indices for germline mutations. There are no definitive treatment guidelines for these patients either. Here, we reviewed previously reported cases of MDS with the Philadelphia translocation with a goal to determine their prognosis and treatment options, specifically the tyrosine kinase inhibitors (TKIs).

\section{Introduction}

MDS is a group of acquired disorders characterized by ineffective and dysplastic hematopoiesis in the bone marrow with variable risk of progression to leukemia. MDS can either be de novo or develop after mutagenic therapy or environmental exposure to toxins, radiation, and chemotherapeutic agents. Symptoms are usually nonspecific, and some patients remain asymptomatic for a long time before diagnosis. Symptoms are based on the cell line involved and can present as fatigue, weakness, dizziness, confusion in case of anemia or infections in neutropenia, or bleeding due to thrombocytopenia or dysfunctional platelets. Philadelphia chromosome is a translocation involving the chromosomes 9 (Abelson protooncogene/ ABL) and 22 (breakpoint cluster region/ $\mathrm{BCR}$ ) with a resultant fusion oncogene which encodes the BCR-ABL protein with enhanced ABL1 activity. It is a disease-defining entity in chronic myeloid leukemia (CML) and is seen in acute lymphoblastic leukemia (ALL) as well but is rarely reported in patients with MDS, and its presence on prognosis or management is not defined. We report a case of MDS with the Philadelphia translocation here and reviewed other similar cases.

\section{Case Report}

A 83-year-old Caucasian male with a past medical history of TIA and nephrolithiasis initially presented for hematologic evaluation of persistent leukocytosis with immature cells on peripheral smear found on routine office visit. On initial evaluation, peripheral smear showed a leukocytosis of 17,500 , with neutrophil predominance of $72 \%$, lymphocytes $10 \%$, monocytes $13 \%$, eosinophils $1 \%$, myelocytes $1 \%$, and blasts $3 \%$. Absolute neutrophil count (ANC) was 2600 cells/ $\mathrm{mcL}$, along with mild anemia, hemoglobin of $11.6 \mathrm{mg} / \mathrm{dl}$, and thrombocytopenia 90,000. His metabolic profile was within normal limits. The patient was asymptomatic except for easy fatigability for few months. No B symptoms were present on initial evaluation.

Initial evaluation with ANA, RA factor, ESR, CRP, iron, ferritin, thyroid function tests, vitamin B12, folate, copper serum, and urine immunofixation tests was normal.

Bone marrow biopsy was done due to suspicion for CML vs. MDS which showed hypercellular marrow $(80 \%$ cellularity) with granulocytic hyperplasia and trilineage dyspoiesis with $<5 \%$ blasts. Fluorescence in situ hybridization (FISH) performed on bone marrow was negative for 
BCR-ABL fusion gene-p190 and p230 isoforms-and was negative for MDS/ AML probes-PDGFRA/ PDGFRB/ FIP1L1/ CHIC2 negative. Cytogenetics was normal with analysis showing 46,XY with no evidence for any clonal structural or numerical abnormality.

Blood CML PCR quantitative panel was negative for b2a2 and b3a2 (p210) and E1a2 (p190) transcripts along with JAK2V617F mutation.

The patient was diagnosed as low-grade (IPSS-R score 2.5 , low risk) myelodysplastic syndrome (MDS) and was monitored as he was mostly asymptomatic and had been doing well. 10 months later, he developed progressive symptomatic anemia, with hemoglobin drop to 8.8 from a baseline of 11.6. Meanwhile, his leukocytosis resolved and thrombocytopenia seemed to improve to $>100,000$. The patient was started on weekly Epoetin alfa with improvement in his anemia. Leukocytosis resolved, but 8 months later, the patient developed significant thrombocytopenia with platelet count drop from 121,000 to 64,000 in 1 week. Workup for thrombocytopenia was initiated with slightly elevated prothrombin time $11.8 \mathrm{sec}$, INR 1.2, and normal PTT. Von Willebrand Factor antigen and Factor III activity were normal. A repeat bone marrow biopsy showed hypercellular marrow for age (approx $80 \%$ cellularity), with trilineage hematopoiesis with significant dysmegakaryopoiesis and mild dyserythropoiesis. No evidence of T or B cell lymphoma or acute leukemia was found.

Flow cytometry on bone marrow specimen revealed neutrophil predominant specimen with 74\% neutrophils, monocytes 3\%, lymphocytes $10 \%$ with normal subtypes, and $2.9 \%$ blasts. Cytogenetics on bone marrow with analysis of 100 interphase cells revealed new BCR-ABL1 fusion gene $\mathrm{t}(9 ; 22)(\mathrm{q} 34 ; \mathrm{q} 11.2)$ with translocation between $22 q 11.2$ and $9 q 34$ in $79 \%$ of cells. Peripheral blood RT PCR for BCR-ABL was positive for BCR-ABL p210 transcript (b2a2 at $11.042 \%$ ). Pt was diagnosed as $\mathrm{Ph}+\mathrm{ve} \mathrm{MDS} / \mathrm{MPN}$, intermediate risk and was started on tyrosine kinase inhibitor imatinib which was discontinued 7 months later due to lack of significant decrease in $\mathrm{Ph}+$ ve clone on repeat marrow biopsy. He was instead started on dasatinib which was discontinued 1 week later due to development of right sided heart failure. He did not have a T315I mutation and was not a candidate for ponatinib. He is currently doing well, 30 months after diagnosis, not requiring transfusion support and is currently waiting for nilotinib approval. His last BCR-ABL level was $9.9 \%$ in peripheral blood at last check 1 month ago.

\section{Discussion}

MDS is a clonal process thought to arise from a single transformed hematopoietic progenitor cell $[1,2]$. The incidence of MDS is variable, but it is estimated to be about 10,000 cases per year, usually diagnosed after the age of 50 $[3,4]$. Common cytogenetic abnormalities associated with MDS include +8 , loss or del of chromosomes 5 or 7 , del $20 \mathrm{q}$ [5]. The BCR-ABL fusion gene is a disease-defining clonal abnormality, usually seen in CML (in >95\%) and in some cases of ALL (17-25\%) [6]. MDS is rarely associated with
TABle 1: Patient characteristics, cytogenetics, time to progression, treatment outcomes, and bone marrow blast percentage

\begin{tabular}{lcccc}
\hline $\begin{array}{l}\text { Blast count } \\
\text { (patients) }\end{array}$ & $\begin{array}{c}<10 \% \\
(n=11)\end{array}$ & $\begin{array}{c}10-20 \% \\
(n=7)\end{array}$ & $\begin{array}{c}>20 \% \\
(n=2)\end{array}$ & $\begin{array}{c}\text { Unavailable } \\
(n=3)\end{array}$ \\
\hline $\begin{array}{l}\text { No progression } \\
\text { Leukemic }\end{array}$ & 5 & 2 & 0 & 1 \\
transformation & 5 & 3 & 2 & 1 \\
No data & 0 & 1 & 0 & 1 \\
RAEBt & 1 & 1 & 0 & 0 \\
\hline
\end{tabular}

BCR-ABL mutation and is usually reported at the time of progression to acute leukemia [7]

A consensus prevalence of the BCR-ABL fusion gene in patients with MDS is currently unavailable. In the study by Keung et $\mathrm{Al}$, the prevalence seems to be about $2 \%$ of cases, but this did not differentiate between de novo and treatment-related MDS [8]. A further literature search revealed a total of 22 cases of MDS with the Philadelphia chromosome. Details of patient characteristics are shown in Table 1, [8-25]. Patients with Philadelphia chromosome like mutations and patients with acquisition of the BCR-ABL gene at the time of evolution to acute leukemia have not been included in the table [26-28].

The Philadelphia chromosome is formed by the translocation of $\mathrm{t}(9: 22)$ with a resultant fusion gene which encodes the oncoprotein BCR-ABL1, with enhanced $\mathrm{ABL}$ tyrosine kinase activity $[29,30]$ leading to increased proliferation of myeloid cells which could lead to transformation of these patients with MDS into acute leukemia. It is estimated that about a third of MDS cases diagnosed will transform into AML, and the BCR/ABL1 translocation is estimated to be present in approximately $1 \%$ of patients with AML [7]. Considering the appearance of the Philadelphia chromosome in patients after or at the time of evolutions to leukemia [20,26-28], it might indicate an overall poorer prognosis.

In addition to known prognostic factors, like cytopenia, bone marrow blast percentage, and karyotype [31], we looked to see if presence of the Philadelphia translocation would lead to increased risk of transformation. Table 2 demonstrates the number of events of progression versus no progression. Of the patients with available data, $n=15$, more than $50 \%(n=8)$ patients transformed to leukemia (including AML, CMML, CML, and myeloid sarcoma) which is much higher than the predicted risk of transformation. 8 of the patients received TKIs, with variable response, but they seem to perform worse with conventional chemotherapy or just supportive care with death due to sepsis being the common reason for mortality. One patient had rising blast count with conventional chemotherapy but responded to imatinib [15]. Overall, patients seem to have a poorer prognosis with increased transformation to leukemia compared to patients without BCRABL mutation and do not respond to conventional chemotherapy or supportive care, although they seem to have a semblance of response with the tyrosine kinase inhibitors.

It is difficult to determine the exact incidence or prognosis of patients with MDS in whom this mutation is 


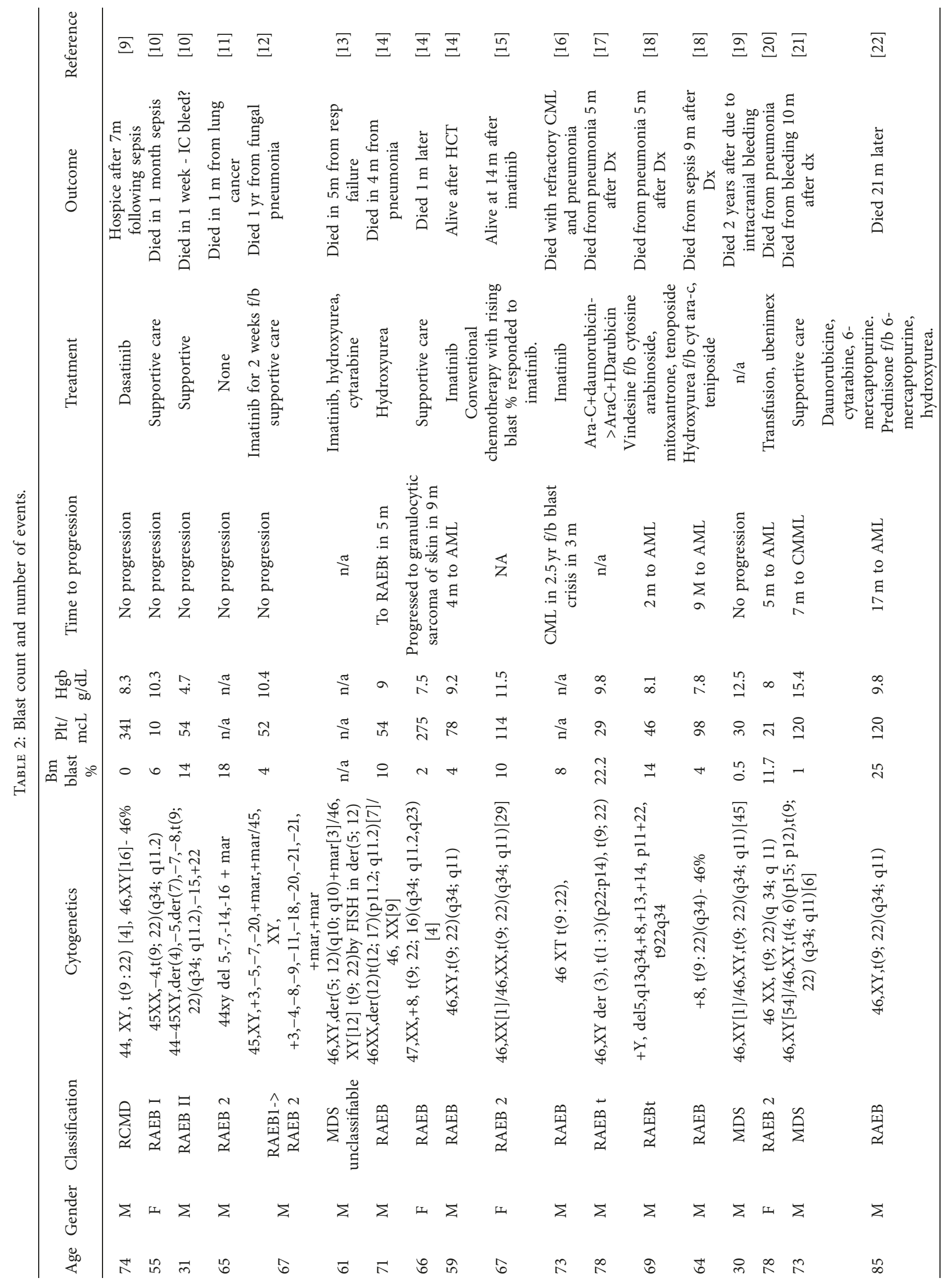




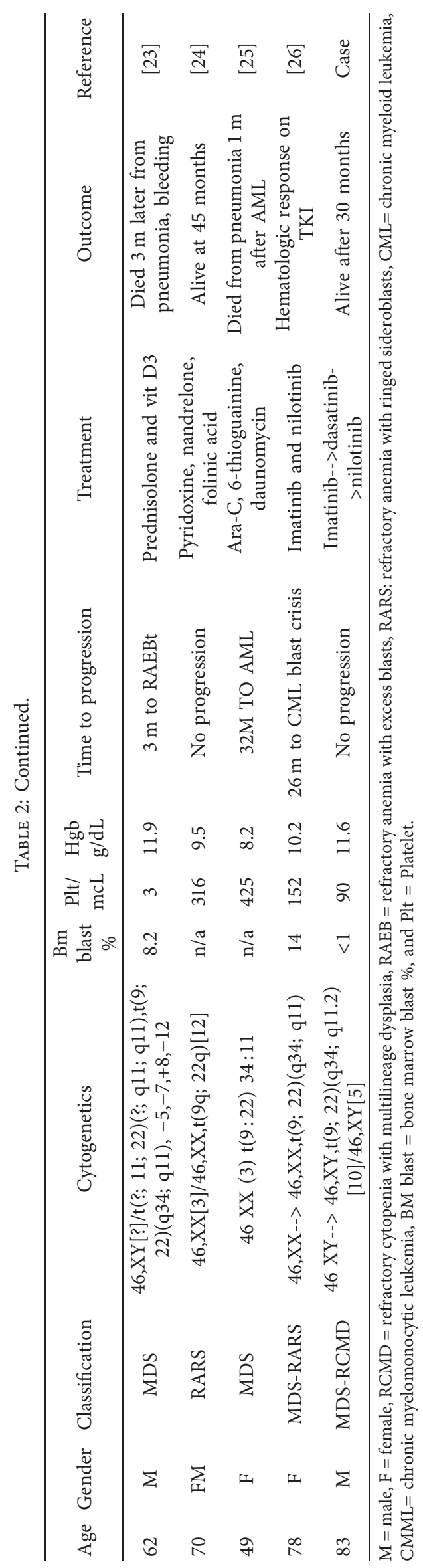


found at this point due to the rarity of its presence, but it would be imperative to suggest that these patients have increased risk of proliferation and probably transformation into leukemias. Routine testing for the Philadelphia translocation is not a part of the NCCN recommendations [32], and it is not part of the MDS panel probe testing for molecular genetics and is not listed in the common gene mutations in NCCN, but this translocation can be identified with conventional cytogenetics and when present, consider treating with tyrosine kinase inhibitors. TKI resistance can occur after treatment with TKIs and checking for T315I mutation in these patients is recommended to switch therapy.

Furthermore, a national database to study the incidence of these mutations and study overall survival and prognosis would be helpful in the future.

\section{Conflicts of Interest}

The authors declare that there are no conflicts of interest regarding the publication of this paper.

\section{Acknowledgments}

Financial support was provided by SSM Health St. Mary's Hospital, Internal Medicine Residency Program.

\section{References}

[1] M. J. Walter, D. Shen, L. Ding et al., "Clonal architecture of secondary acute myeloid leukemia," New England Journal of Medicine, vol. 366, no. 12, pp. 1090-1098, 2012.

[2] P. S. Woll, U. Kjällquist, O. Chowdhury et al., "Myelodysplastic syndromes are propagated by rare and distinct human cancer stem cells in vivo," Cancer Cell, vol. 25, no. 6, pp. 794-808, 2014.

[3] M. A. Sekeres, W. M. Schoonen, H. Kantarjian et al., "Characteristics of US patients with myelodysplastic syndromes: results of six cross-sectional physician surveys," JNCI Journal of the National Cancer Institute, vol. 100, no. 21, pp. 1542-1551, 2008.

[4] http://www.cancer.net/cancer-types/myelodysplastic-syndromesmds/statistics.

[5] A. S. Sperling, C. J. Gibson, and B. L. Ebert, "The genetics of myelodysplastic syndrome: from clonal hematopoiesis to secondary leukemia," Nature Reviews Cancer, vol. 17, no. 1, pp. 5-19, 2017.

[6] A. K. Fielding, "How I treat Philadelphia chromosomepositive acute lymphoblastic leukemia," Blood, vol. 116, no. 18, pp. 3409-3417, 2010.

[7] K. Kakihana, D. Mizuchi, M. Yamaguchi et al., "Late appearance of Philadelphia chromosome with the p190 BCR/ $\mathrm{ABL}$ chimeric transcript in acute myelogenous leukemia progressing from myelodysplastic syndrome," Rinsho Ketsueki, vol. 44, pp. 242-248, 2003, [in Japanese].

[8] Y. K. Keung, M. Beaty, B. L. Powell, I. Molnar, D. Buss, and M. Pettenati, "Philadelphia chromosome positive myelodysplastic syndrome and acute myeloid leukemia-retrospective study and review of literature," Leukemia Research, vol. 28, no. 6, pp. 579-586, 2004.

[9] A. Armas, C. Chen, M. Mims, and G. Rivero, "Uncovering clinical features of de novo philadelphia positive myelodysplasia," Case Reports in Hematology, vol. 2017, Article ID 5404131, 5 pages, 2017.

[10] K. Rahman, M. KumarSingh, R. Gupta, S. Dutta, and S. Nityanand, "De novo Philadelphia chromosome positive myelodysplastic syndrome: report of two cases with brief literature review," Journal of Cancer Research and Therapeutics, 2018, in press.

[11] B. Y. Seo, J. H. Lee, M. G. Kang et al., "Cryptic ela2 BCRABL1 fusion with complex chromosomal abnormality in de novo myelodysplastic syndrome," Annals of Laboratory Medicine, vol. 35, no. 6, pp. 643-645, 2015.

[12] S. Dutta, P. Kumari, K. S. Natraj et al., "Philadelphia chromosome-positive myelodysplastic syndrome: is it a distinct entity?," Acta Haematologica, vol. 129, no. 4, pp. 215217, 2013.

[13] M. Manabe, Y. Yoshii, S. Mukai et al., "Late appearing Philadelphia chromosome as another clone in a patient with myelodysplastic syndrome harboring $\operatorname{der}(5 ; 12)(\mathrm{q} 10 ; \mathrm{q} 10)$ at diagnosis," Rinsho Ketsueki, vol. 53, no. 6, pp. 618-622, 2012.

[14] M. W. Drummond, C. J. Lush, M. A. Vickers, F. M. Reid, J. Kaeda, and T. L. Holyoake, "Imatinib mesylate-induced molecular remission of Philadelphia chromosome-positive myelodysplastic syndrome," Leukemia, vol. 17, no. 2, pp. 463-465, 2003.

[15] M. Onozawa, T. Fukuhara, M. Takahata, Y. Yamamoto, T. Miyake, and I. Maekawa, "A case of myelodysplastic syndrome developed blastic crisis of chronic myelogenous leukemia with acquisition of major BCR/ABL," Annals of Hematology, vol. 82, no. 9, pp. 593-595, 2003.

[16] T. Wakayama, Y. Maniwa, H. Ago, N. Kakazu, and T. Abe, "A variant form of myelodysplastic syndrome with $\mathrm{Ph}$ - minorBCR/ABL transcript," International Journal of Hematology, vol. 74, no. 1, pp. 58-63, 2001.

[17] J. F. Lesesve, X. Troussard, C. Bastard et al., "p190bcr/abl rearrangement in myelodysplastic syndromes: two reports and review of the literature," British Journal of Haematology, vol. 95, no. 2, pp. 372-375, 1996.

[18] Y. Xue, R. Zhang, Y. Guo, J. Gu, and B. Lin, "Acquired amegakaryocytic thrombocytopenic purpura with a Philadelphia chromosome," Cancer Genetics and Cytogenetics, vol. 69, no. 1, pp. 51-56, 1993.

[19] H. Mori, N. Takahashi, J. Tada et al., "RAEB transformed into AML (M0) showing Ph 1 chromosome and rearrangement of major cluster region," Rinsho Ketsueki, vol. 34, no. 11, pp. 1458-1463, 1993.

[20] G. Verhoef, P. Meeus, M. Stul et al., "Cytogenetic and molecular studies of the Philadelphia translocation in myelodysplastic syndromes. Report of two cases and review of the literature," Cancer Genetics and Cytogenetics, vol. 59, no. 2, pp. 161-166, 1992.

[21] N. Smadja, M. Krulik, A. Hagemeijer, D. C. van der Plas, G. Gonzalez Canali, and A. de Gramont, "Cytogenetic and molecular studies of the Philadelphia translocation $\mathrm{t}(9 ; 22)$ observed in a patient with myelodysplastic syndrome," Leukemia, vol. 3, no. 3, pp. 236-238, 1989.

[22] K. Toyama, K. Ohyashiki, and J. H. Ohyashiki, "Molecular implications of $\mathrm{Ph}(+)$ myelodysplastic syndrome," in $\mathrm{Ad}$ vances in Experimental Medicine and Biology, vol. 241, pp. 67-71, Springer Nature Switzerland AG, Basel, Switzerland, 1988.

[23] A. Berrebi, R. Bruck, M. Shtalrid, and J. Chemke, "Philadelphia chromosome in idiopathic acquired sideroblastic anemia," Acta Haematologica, vol. 72, no. 5, pp. 343-345, 1984. 
[24] D. G. Roth, C. M. Richman, and J. D. Rowley, "Chronic myelodysplastic syndrome (preleukemia) with the Philadelphia chromosome," Blood, vol. 56, no. 2, pp. 262-264, 1980.

[25] L. Zhang, J. M. Bennett, X. Zhang et al., "Uncommon of the uncommon: low-grade myelodysplastic syndrome evolving into chronic myelogenous leukemia," Journal of Clinical Oncology, vol. 29, no. 15, pp. e434-e436, 2010.

[26] K. Kakihana, D. Mizuchi, M. Yamaguchi et al., "Miura O Late appearance of the Philadelphia chromosome with the p190 $\mathrm{Bcr} / \mathrm{Abl}$ chimeric transcript in acute myelogenous leukemia progressing from myelodysplastic syndrome," Rinsho Ketsueki-Japanese Journal of Clinical Hematology, vol. 44, pp. 242-248, 2003.

[27] A. Fukunaga, H. Sakoda, Y. Iwamoto et al., "Abrupt evolution of Philadelphia chromosome-positive acute myeloid leukemia in myelodysplastic syndrome," European Journal of Haematology, vol. 90, no. 3, pp. 245-249, 2013.

[28] T. Kohno, T. Amenomori, S. Atogami et al., "Progression from myelodysplastic syndrome to acute lymphoblastic leukaemia with Philadelphia chromosome and p190 BCR-ABL transcript," British Journal of Haematology, vol. 93, no. 2, pp. 389-391, 1996.

[29] F. Zhou, R. Jin, Y. Hu, and H. Mei, “A novel BCR-ABL1 fusion gene with genetic heterogeneity indicates a good prognosis in a chronic myeloid leukemia case," Molecular Cytogenetics, vol. 10, no. 1, p. 19, 2017.

[30] M. Paridar, O. K. Ghalesardi, M. Seghatoleslami, A. Ahmadzadeh, A. Khosravi, and N. Saki, "Cytogenetic and molecular basis of BCR-ABL myelodysplastic syndrome: diagnosis and prognostic approach," Journal of Cancer Metastasis and Treatment, vol. 3, no. 2, pp. 38-44, 2017.

[31] J. Shi, Z. H. Shao, H. Liu et al., "Transformation of myelodysplastic syndromes into acute myeloid leukemias," Chinese Medical Journal, vol. 117, no. 7, pp. 963-967, 2004.

[32] NCCN guidelines, http://www.nccn.org/professionals/physician_ gls/pdf/mds. 


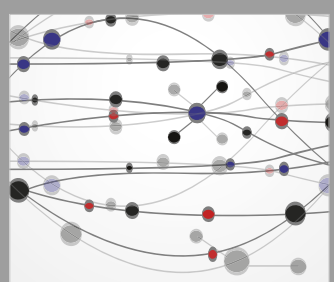

The Scientific World Journal
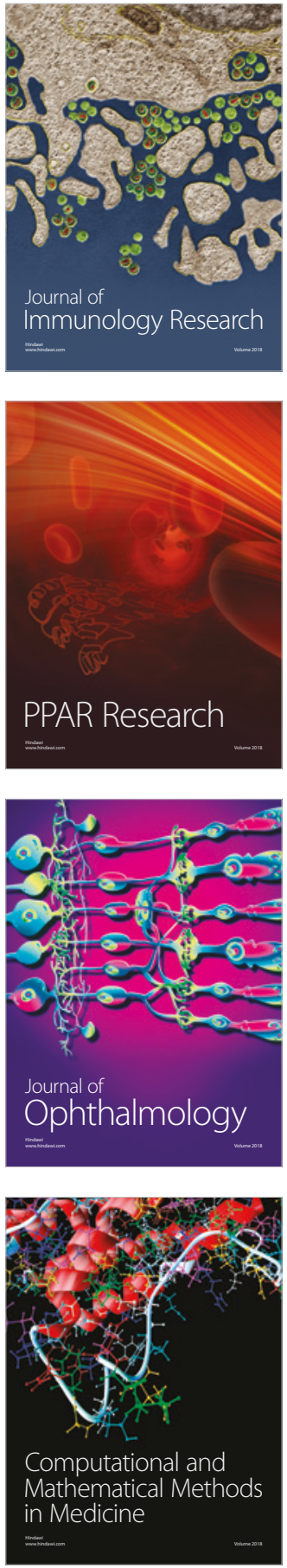

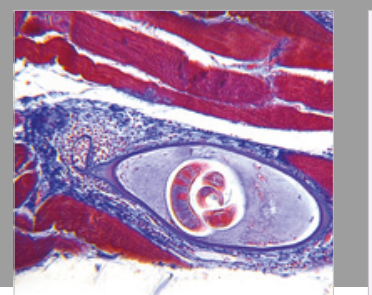

Gastroenterology Research and Practice

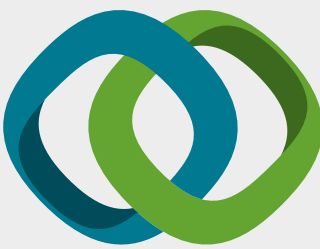

\section{Hindawi}

Submit your manuscripts at

www.hindawi.com
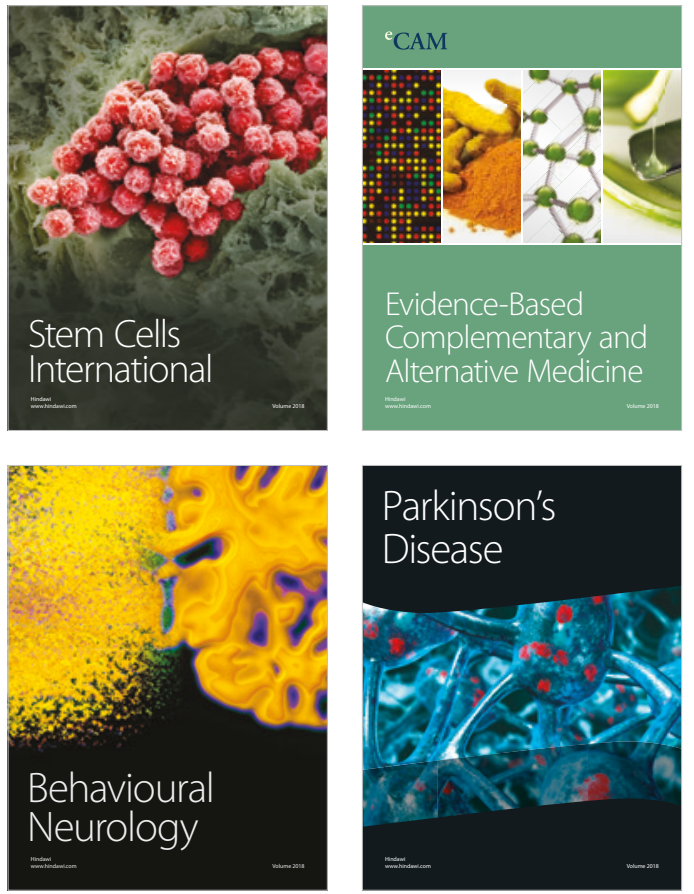

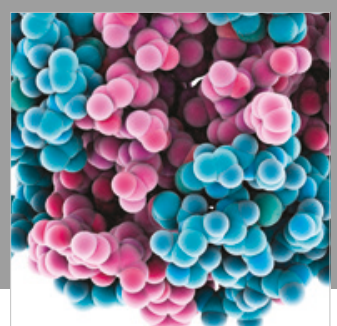

ournal of

Diabetes Research

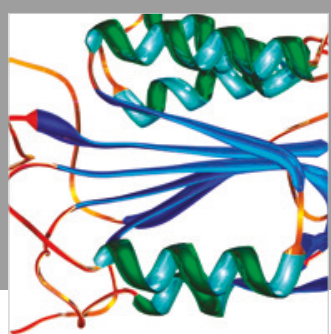

Disease Markers
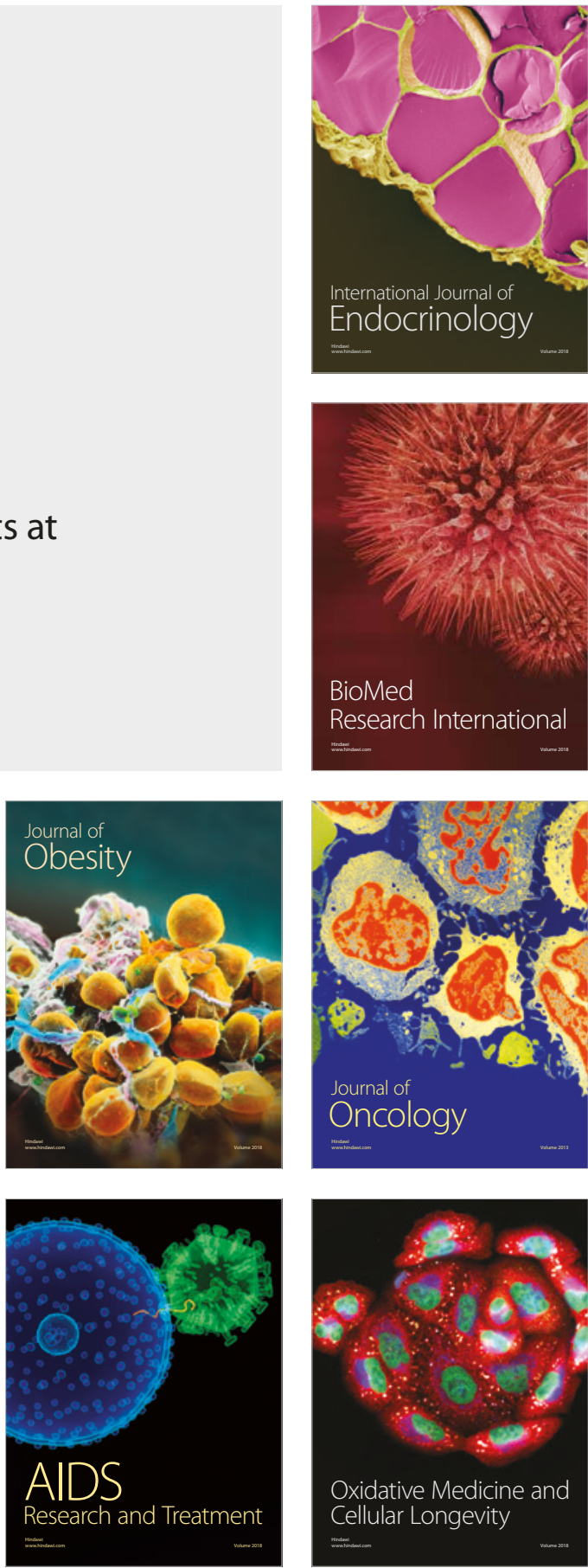